\title{
The Study of the Toxicity of the Gas Released on Lithium Ion Battery during Combustion
}

\author{
Jinghui Chen ${ }^{1}$, Fei $\mathrm{Gao}^{2}$, Xiangmei $\mathrm{Li}^{1, *}$, Kai Yang ${ }^{2}$, Songcen Wang ${ }^{2}$ and RongjieYang ${ }^{1}$ \\ ${ }^{1}$ School of Material Science and Engineering, Beijing Institute of Technology, National Engineering Research Center of Flame \\ Retardant Material, Beijing 100081, China \\ ${ }^{2}$ China Electric Power Research Institute, Beijing 100019, China \\ *Corresponding author
}

\begin{abstract}
Lithium ion battery and its safety are taken more consideration with fossil energy consuming and the reduction requirement of $\mathrm{CO} 2$ emission. The safety problem of lithium ion battery is mainly contributed by thermal runaway caused fire and explosion. When the lithium ion battery fire and explosion, gases released by the burning lithium ion battery have toxicity, and will cause harm to human. This paper reviews the hazard rating of the gas released by the burning lithium ion batteries through a series of biological and chemical methods.
\end{abstract}

\section{Keywords-lithium ion battery; gas; toxicity; combustion}

\section{INTRODUCTION}

For far too long we have been dependent on fossil fuels to heat our homes, to power our industries, and for transportation ${ }^{[1]}$.However fossil fuels are a nonrenewable resource, and once they are gone, they can no longer be part of our energy mix. At the same time, the burning of fossil fuels is blamed for emissions that contribute to global climate change, acid rain, and ozone problems ${ }^{[2]}$

Accordingly, measures are being adopted in a variety of different fields to help prevent global warming by reducing $\mathrm{CO}_{2}$ emissions. More importantly, advances in environmental technology, such as the emergence of hybrid electric vehicles (HEVs) in the 1990s, have brought innovation to an era where vehicles have been traditionally powered by gasoline. As more renewable energy sources are integrated into the smart grid, managing and storing energy is essential, in particular, large-scale diurnal storage. These may be very dangerous.

Lithium ion battery (LIB) as a kind of new energy is getting more and more attention due to the worldwide energy short-age ${ }^{[3]}$. Lithium ion batteries are mainly made of electrolyte and active materials, which comprise a very promising energy storage medium for electric and hybrid electric vehicles compared to other energy storage approaches. Because of their lightness and high energy density, lithium ion batteries are ideal for portable devices, such as laptops. In addition, lithium ion batteries have no memory effect and do not use poisonous metals, such as lead, mercury or cadmium. However, these batteries have not been widely deployed commercially in these vehicles yet due to safety, cost, and poor low temperature performance, which are all challenges

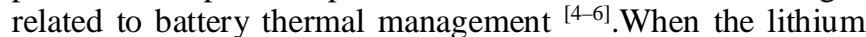
ion battery fire and explosion, gases from the burning of lithium ion battery have toxicity, and will cause harm to humans body.

The purpose of this paper is to report the hazard rating of the burning gas of lithium ion batteries by a series of chemical and biological tests.

\section{EXPERIMENTS}

\section{A Experiment Equipment}

Stopwatch; ruler; Thermometer; Flue gas producing apparatus; Blance; Infrared analyzing instrument; Chamber; Sampling System; Colorimetric Gas Detector Tubes.

YD - type 1 the toxicity of the smoke test instrument

\section{$B$ Experiment Method}

This test accord to TB/T 3237-2010 mu trains with built-in toxic gas analysis "material flame retardant technology condition in clause 4.4.Gas recovery test method accord to GB/T 8323.2 2008 plastic smoke generated part 2: single chamber method determination of smoke density test method.

According to TB/T 3237-2010 clause 4.4.3.1, the analysis of $\mathrm{CO}$ and $\mathrm{CO}_{2}$ use the infrared analyzing instrument to detect the gas content. In accordance with the terms of this TB/T 3237-2010 4.4.3.5, the gas released by the burning lithium ion batteries such as the $\mathrm{SO}_{2}, \mathrm{HCl}, \mathrm{HBr}, \mathrm{HF}, \mathrm{HCN}, \mathrm{NOx}$, use the Colorimetric Gas Detector Tubes to test.

\section{RESULTS AND DISCUSSION}

Model:Radiation intensity of illumination is $25 \mathrm{~kW} / \mathrm{m}^{2}$ with a pilot flame.

The Sample Size: $75 \mathrm{~mm} \times 75 \mathrm{~mm}$

TABLE I THE GAS OF RELEASED BY THE BURNING LITHIUM ION BATTERIES

\begin{tabular}{|c|c|c|c|}
\hline Gas & $\begin{array}{c}\text { Required concentration } \\
\mathrm{mg} / \mathrm{m}^{3}(\mathrm{ppm})\end{array}$ & $\begin{array}{c}\text { The measured } \\
\text { values(ppm) }\end{array}$ & $\begin{array}{c}\text { Qualified } \\
\text { or Unqualified }\end{array}$ \\
\hline $\mathrm{CO}$ & $<4000(3500)$ & 28400 & Qualified \\
\hline $\mathrm{CO}_{2}$ & $<90000(50000)$ & 650 & Qualified \\
\hline $\mathrm{HF}$ & $<82(100)$ & 0 & Qualified \\
\hline $\mathrm{HBr}$ & $<330(100)$ & 0 & Qualified \\
\hline
\end{tabular}




\begin{tabular}{|c|c|c|c|}
\hline $\mathrm{HCl}$ & $<150(100)$ & 0 & Qualified \\
\hline $\mathrm{NO}_{\mathrm{x}}$ & $<190(100)$ & 16 & Qualified \\
\hline $\mathrm{SO}_{2}$ & $<260(100)$ & 10 & Qualified \\
\hline $\mathrm{HCN}$ & $<110(100)$ & 1 & Qualified \\
\hline
\end{tabular}

The lithium ion batteries burned quickly and emitted more poisonous and harmful gases at $25 \mathrm{~kW} / \mathrm{m}^{2}$ thermal radiation from table 1. After $4 \mathrm{~min}$, using the Colorimetric Gas Detector Tubes detected the gas content. The result showed that as the lithium ion batteries burning, five gases were released, and all the gases were in the safe concentration range and qualified.

To judge the level of the biological toxicity of the burning gas of lithium ion batteries, the conditions of the experiment is full of smoke and no flame gas. According to the material test results, the result of the experiment should be fully considered whether death or weight loss. If infected mouse are dead in 30 minutes and is dangerous. On the contrary, if average weight of infected mouse can recover to the test weight in three days and still alive, the class is the highest production smoke concentration limit. The biological toxic classification of fire effluents hazard of the burning lithium ion batteries was listed Table 2.

TABLE II THE BIOLOGICAL TOXICITY OF THE GAS RELEASED BY THE BURNING LITHIUM ION BATTERIES

\begin{tabular}{|c|c|c|c|}
\hline $\begin{array}{c}\text { Sample } \\
\text { name }\end{array}$ & $\begin{array}{c}\text { Experiment } \\
\text { Method }\end{array}$ & Rank & Result \\
\hline $\begin{array}{c}\text { Battery } \\
\text { Diaphragm }\end{array}$ & $\begin{array}{c}\text { GB/T } \\
20285-2006\end{array}$ & $\mathrm{ZA}_{2}$ & Qualified \\
\hline
\end{tabular}

\section{CONCLUSION}

The burning lithium ion battery can release six chemical compounds, included $\mathrm{CO}, \mathrm{CO}_{2}, \mathrm{NO}_{\mathrm{X}}, \mathrm{SO}_{2}$ and $\mathrm{HCN}$. But the concentration of all toxic gases was qualified. The rank of biological toxicity of burning lithium was $\mathrm{ZA}_{2}$, and qualified too.

\section{REFERENCES}

[1] P. Poizot, F. Dolhem, Energy Environ. Sci. 4 (2011) 2003-2019

[2] B. Scrosati. J. Power Sources 195(2010) 2419-2430

[3] J.Y.Lee, D.Deng, M.G.Kim, J.Cho, Energy Environ. Sci. 2 (2009) 818-837

[4] T.M. Bandhauer, S. Garimella, T.F.Fuller, J. Electrochem. Soc. 158 (2011) R1-R25.

[5] J.B. Goodenough, Y.Kim, Chem. Mater. 22 (2010) 587-603

[6] J.M.Tarascon, M.Armand, Nature 414 (2001) 359-367 